\title{
Identification of Chatter Vibrations and Active Vibration Control by Using Sliding Mode Controller on Dry Turning of Ti6al4v
}

\author{
Mehmet Ali GUVENC \\ Iskenderun Technical University \\ Hasan Huseyin BILGIC \\ Iskenderun Technical University \\ Selçuk MISTIKOĞLU ( $\nabla$ selcuk.mistikoglu@iste.edu.tr) \\ Iskenderun Teknik Universitesi https://orcid.org/0000-0003-2985-8310
}

\section{Research Article}

Keywords: Chatter, Sliding Mode Controller, Active Vibration Control, Turning, Ti6Al4V

Posted Date: February 9th, 2021

DOI: https://doi.org/10.21203/rs.3.rs-172886/v1

License: (c) (i) This work is licensed under a Creative Commons Attribution 4.0 International License.

Read Full License 


\title{
IDENTIFICATION OF CHATTER VIBRATIONS AND ACTIVE VIBRATION CONTROL BY USING SLIDING MODE CONTROLLER ON DRY TURNING OF TI6AL4V
}

\author{
Mehmet Ali Guvenc ${ }^{1}$, Hasan Huseyin Bilgic ${ }^{2}$, and Selcuk Mistikoglu ${ }^{3 *}$ \\ ${ }^{1,2,3}$ Department of Mechanical Engineering, \\ Iskenderun Technical University, 31200 Iskenderun \\ Iskenderun, Hatay, Turkey. \\ Email: ${ }^{1}$ mali.guvenc@iste.edu.tr; ${ }^{1}$ hhuseyin.bilgic@iste.edu.tr; ${ }^{1 *}$ selcuk.mistikoglu@iste.edu.tr \\ * Corresponding Author
}

\begin{abstract}
In recent years, with the development of sensor technologies, communication platforms, cyber physical systems, storage technologies, internet applications and controller infrastructures, the way has been opened to produce competitive products with high quality and low cost. In turning, which is one of the important processes of machining, chatter vibrations are among the biggest problems affecting product quality, productivity and cost. There are many techniques proposed to reduce chatter vibrations for which the exact cause cannot be determined. In this study, an active vibration control based on Sliding Mode Control (SMC) has been implemented in order to reduce and eliminate chatter vibration, which is undesirable for the turning process. In this context, three-axis acceleration data were collected from the cutting tool during the turning of Ti6Al4V. Finite Impulse Response (FIR) filtering, Fast Fourier Transform (FFT) analysis and integral process were carried out in order to use the raw acceleration data collected over the system in control. The system was modeled mathematically and an active control block diagram was created. It was observed that chattering decreased significantly after the application of active vibration control. The surface quality formed by the amplitude of the graph obtained after active control has been compared and verified with the data obtained from the actual manufacturing result.
\end{abstract}

KEYWORDS: Chatter, Sliding Mode Controller, Active Vibration Control, Turning, Ti6Al4V

\section{INTRODUCTION}

In recent years, smart manufacturing applications have found a wide range of uses in machining [1-3]. Increasing the quality in the machining process is possible by reducing and controlling the vibrations (chatter) that occur during production. Chatter vibrations in turning and milling, which are among the most widely used methods in machining, cause important problems and directly affect the cost and product quality [4-7].

Chatter vibrations occurring during machining may cause early completion of the life of the cutting tool, increase in surface roughness of the workpiece and damage to machine parts. Chattering is a classic problem that occurs frequently and reduces production efficiency. This event is a situation that the operator often encounters and the cause is not entirely clear. Due to the chatter vibrations, the changes in chip thickness increase and this causes the formation of marks on the processed surface with the sound [8,9]. These chatter vibrations, which are constantly encountered in machining applications, should be avoided without sacrificing quality and efficiency [10]. For this reason, identification of chatter vibration and chatter suppression has been a subject of interest to 
researchers working in the field of machining. To overcome these problems, various techniques have been developed by researchers to detect, reduce and control of chatter vibration. Techniques suggested in the literature include determining of the effects of machining parameters on product quality, prediction of machining parameters for the best product quality, optimization of machining parameters, tracking/monitoring of the machining process, identification/detection of chatter vibrations, real time control of chatter during machining $[11,12]$.

Passive control of the chatter vibrations during turning is an easy, applicable and efficient approach with correct element selection. The basis of the reduction of chatter vibration by passive control is the spring and damping element design suitable for the system frequency and amplitude [4]. However, the trend towards active control applications with different methods for higher product quality has increased. In active vibration control applications in turning; There are stages of measuring the vibrations occurring during processing accurately, filtering/analyzing the measured data and creating an external impact force that can dampen the chatter vibration [13].

There are many studies in the literature on the determination, identification, prediction and control of chatter. Alternative techniques to reduce chatter have been studied by J. Munoa et al. They proposed progressive solutions to design and control approaches and examined the success of the existing methods used to improve the cutting process. In the study in which passive control and active control applications and future expectations were discussed, it was argued that active vibration control promises hope for the future in reducing chattering $[4,13,14]$.

The chatter vibration generated during turning has high frequency and low amplitude. Therefore, sensors, data acquisition devices and actuators used in active vibration control must have high speed and precision. In a study conducted to measure the vibration values that occur on the cutting tool and are constantly increasing, Jang and Tarng used piezo-electric sensors and measured and compared the controlled and uncontrolled vibration frequencies occurring in the cutting tool. They observed that the controlled vibration frequency values are $90 \%$ less than the uncontrolled vibration frequency values [15].

MR and ER fluids are among the systems commonly used in active vibration control applications. Mei et al. performed MR-based active vibration control for the boring process and achieved great success [16]. In addition to these, piezoelectric patches and actuators have expanded the application area thanks to their high operating frequencies and precision. Harms et al. Designed and implemented a piezoelectric-based cutting tool for active control on the lathe [17]. Haifeng et al. implemented a piezo-based active vibration control to suppress chatter vibrations that occur during the turning process [18].

As seen from the studies given above and in literature, there are many studies on the identification, examination and control of chatter vibrations occurring during turning. However, it has been seen that there is not sufficient study on the determination of chatter vibrations during the turning of the Ti6Al4V alloy and the active control of these vibrations. It has been observed that the active chatter suppression studies in turning are generally carried out with classical control applications. By this 
paper, it is aimed to identification of chatter vibrations and active control of chatter by using SMC which is known robust, stable and optimal for Ti6Al4V.

In this study, an active vibration control application working with a Sliding Mode based has been implemented in order to reduce the chatter, which adversely affects product quality, tool life and productivity in turning, during production. In this context, three-axis acceleration data were collected on the tool during machining, the collected data was filtered, and the double integral was taken for the displacement data, and then chatter analysis was performed using the Fast Fourier Transform (FFT) method. Active force control was carried out with the help of the mathematical model created.

\section{EXPERIMENTAL STUDY}

In the experimental studies, Quantum turning lathe and Ti6Al4V titanium alloy workpiece with dimensions of $\varnothing 28 \mathrm{~mm}$ X $250 \mathrm{~mm}$ was used. Experiments were carried out with the processing parameters determined for this alloy. The image of the experiment set is given in Fig. 1. Constant parameters used in the experiments are given in Table 1.

Table 1. Constant parameters used in experimental studies

\begin{tabular}{ll}
\hline Workpiece Material & Ti6Al4V \\
Cutting Tool & Tungsten Carbide \\
Depth of Cut, $a(\mathrm{~mm})$ & 1 \\
Cutting Speed, $V(\mathrm{~m} / \mathrm{min})$ & 50 \\
Feed Rate, $V_{c}(\mathrm{~mm} / \mathrm{rev})$ & 0.3 \\
\hline
\end{tabular}

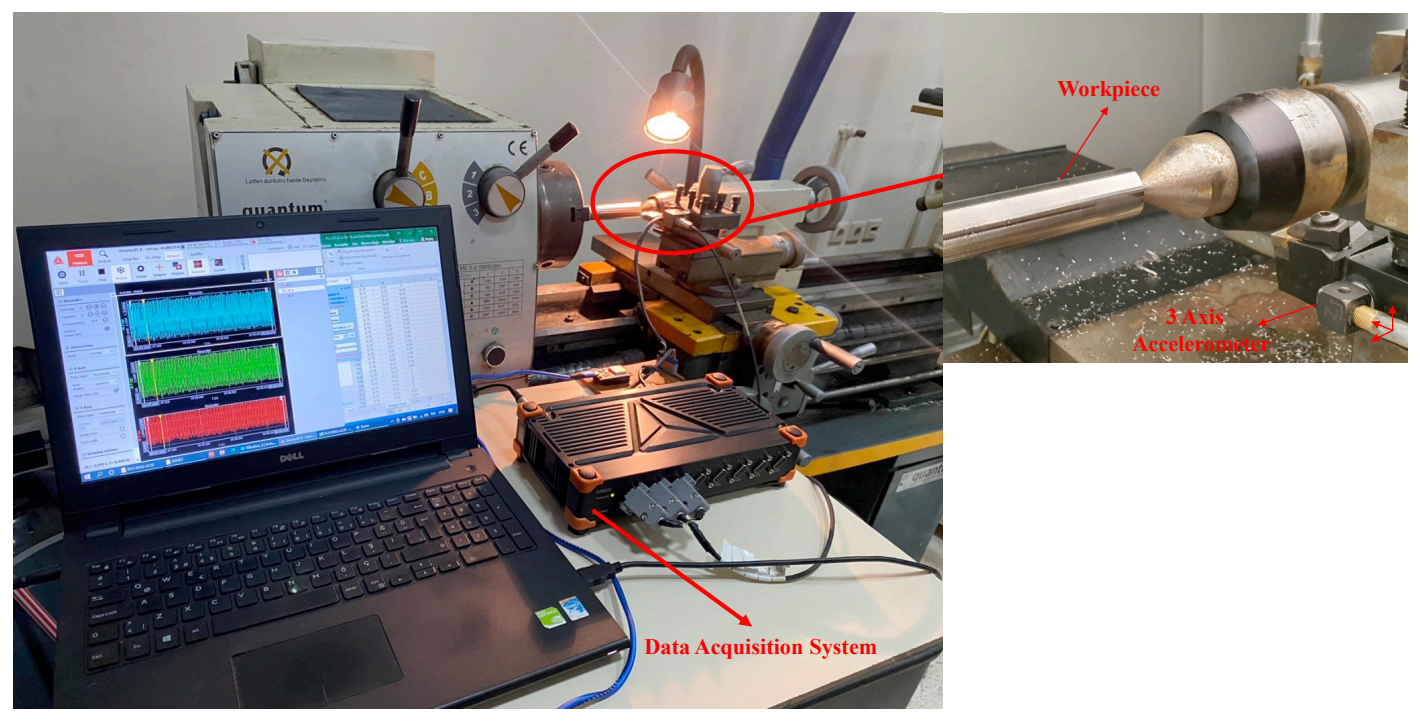

Fig. 1. Experimental setup for vibration measurement 
Ti6Al4V (Titanium Grade 5) Ti alloy used as a workpiece has a wide range of uses such as military equipment, navy, protection, aerospace, medical technology, ultrasonic thanks to its low specific gravity and high mechanical properties $[19,20]$. Ti alloys are generally selected according to phase transformations and Ti6Al4V alloy is in the $\alpha / \beta$ group. This alloy is often seen in aircraft landing gear, gas turbines, and implant applications. It is possible to see that Ti6Al4V alloy is frequently produced by casting, forging and machining methods, as well as powder metallurgy [21]. The chemical composition and mechanical properties of Ti6Al4V alloy are given in Table 2 and Table 3 , respectively.

Table 2. The chemical composition of Ti6Al4V (\%)

\begin{tabular}{llllllll}
\hline Al & $\mathbf{V}$ & $\mathbf{C}$ & $\mathbf{F e}$ & $\mathbf{O}$ & $\mathbf{N}$ & $\mathbf{H}$ & $\mathbf{T i}$ \\
\hline $5,5-6,5$ & $3,5-4,5$ & 0,08 & 0,25 & 0,13 & 0,03 & 0,012 & Kalan \\
\hline
\end{tabular}

Table 3. Mechanical properties of Ti6Al4V

\begin{tabular}{ll}
\hline Mechanical properties & \\
\hline Density $\left(\mathrm{g} / \mathrm{cm}^{3}\right)$ & 4,45 \\
Specific heat $(\mathrm{J} /(\mathrm{g} \times \mathrm{K}))$ & 0,56 \\
Thermal conductivity $(\mathrm{W} /(\mathrm{m} \times \mathrm{K}))$ & 7,1 \\
Elasticity modulus $\left(\mathrm{KN} / \mathrm{mm}^{2}\right)$ & 114 \\
Thermal elongation $(10-6 / \mathrm{K})$ & 8,9 \\
Tensile strength $(\mathrm{MPa})$ & 892 \\
Yield limit $(\mathrm{MPa})$ & 828 \\
Elongation $(\%)$ & 10 \\
\hline
\end{tabular}

\subsection{Theoretical Background}

There are two types of vibration in machining: spontaneous and forced vibration. These vibrations cause deterioration of the surface quality. It also wears the cutting tool, shortening its life and damaging the components of the bench. Forced vibration is a vibration that occurs as a result of the mechanical movements of the machine. The spontaneous vibration, on the other hand, occurs separately from the machine and external factors due to chip removal. This vibration is also called chatter vibration $[11,22]$.

Chatter vibrations, which are seen as spontaneous vibrations during turning, are caused by machining forces, chip cross-section and changes in tool geometry. Due to the complex nature of the chatter vibrations, the cutting forces that occur during turning activate one of the structural modes of the cutting tool and the workpiece system, causing a wavy surface on the workpiece. It is of great importance to recognize the system elements in order to identify and control the chatter vibrations. 
Within the scope of this study, system modeling was carried out for the active vibration control application. The mechanism of chatter vibration is shown in Fig. 2. In this mechanism, m, $\mathrm{k}, \mathrm{c}$ are the tool parameters and refer to mass, spring constant and damping coefficient, respectively.

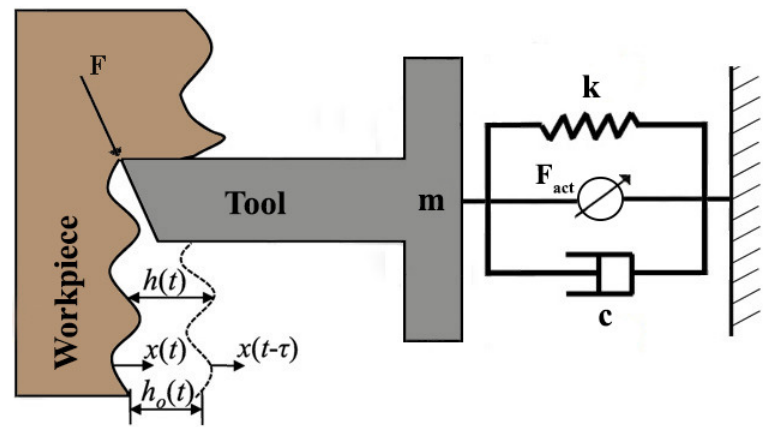

Fig. 2. System modeling in turning

Time dependent mathematical expression of sawdust is shown in Eq. 1. In the equation, the displacement of the cutting point over time with respect to the position in the previous cycle is expressed as $x(t)-x(t-\tau)$, where $h_{s}$ is the thickness of the uncut chip. In the equation, it is defined as $\tau=60 / N$, where $\mathrm{N}$ represents the rotation speed of the spindle in $\mathrm{rev} / \mathrm{m}$.

$$
h(t)=h_{S}-x(t)+x(t-\tau)
$$

The equation expressing the system behavior during turning is presented in Eq. 2. Here, $F_{c}$ is the cutting force, $\mathrm{b}$ is the depth of cut, $K_{f}$ is the specific cutting coefficient. Specific cutting coefficient varies depending on the physical and mechanical properties of the material.

$$
m \ddot{x}(t)+c \dot{x}(t)+k x(t)=F_{c}(t) \equiv K_{f} b\left(h_{S}-x(t)+x(t-\tau)\right)
$$

In active control applications, an external actuating force is required to keep the tool vibration at the desired level. As expressed in Figure 2, the acting force has been designed to affect the tool. In case the actuator force is added to the system, the mathematical model will be as in Eq. 3. Fact represents the impact force generated by the actuator.

$$
m \ddot{x}(t)+c \dot{x}(t)+k x(t)=K f^{b\left(h_{S}-x(t)+x(t-\tau)\right)+F_{a c t}(t)}
$$

The process parameters used to ensure real situations are [18, 23, 24]: mass $(m)=2.5 \mathrm{~kg}$, stiffness $(k)=2 \times 10 \mathrm{~N} / \mathrm{m}$, damping $(c)=1340 \mathrm{~N} . \mathrm{s} / \mathrm{m}$ and cutting coefficient $\left(K_{f}\right)=2000 \mathrm{~N} / \mathrm{m}$. Equation 4 is obtained if the transfer function between force and displacement for the cutting tool is defined as $\phi(s)$. With the addition of $F_{a c t}$ to the system for Figure 4, which is adapted for the closed loop feedback control strategy, the general transfer function of our system is obtained as in Equation 5 and the system transfer function in Equation 6.

$$
x(s)=\phi(s)\left(F_{c}(s)+F_{a c t}(s)\right)
$$




$$
\begin{aligned}
& x(s)=\phi(s)\left(K_{f} b\left(h_{s}+x(s)\left(e^{-s \tau}-1\right)\right)+F_{a c t}(s)\right) \\
& G(s)=\frac{X(s)}{F(s)}=\frac{1}{m s^{2}+c s+k}=\frac{C}{s^{2}+A s+B}
\end{aligned}
$$

\subsection{Data Acquisition}

Within the scope of this study, the acquisition of vibration data generated during surface turning of Ti6V4Al alloy workpiece was performed with Dewesoft/Sirius, which provides a flexible, modular, expandable and safe working environment (Fig. 3a). The most important features of SIRIUS are that it prevents errors frequently encountered during the measurement process, is simple to use and has a user-friendly data processing software.

a)

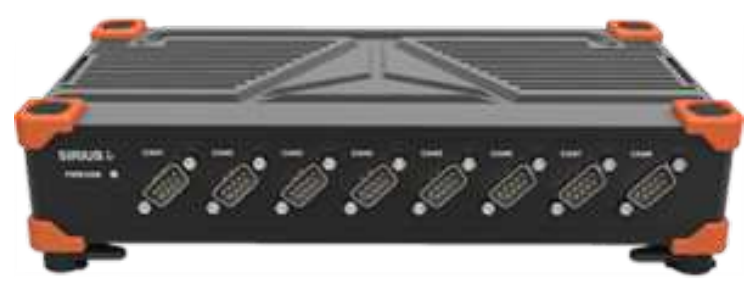

b)

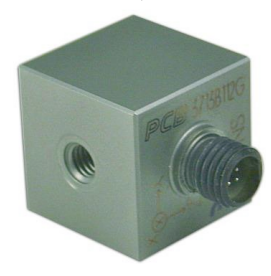

Fig. 3. a) Dewesoft Data acquisition device b) MEMS triaxial accelerometer

MEMS type PCB/3713B1130G brand accelerometer was used to collect 3-axis acceleration data on the machine tool (Fig. 3b). The accelerometer has a measurement range of $\pm 30 \mathrm{~g}$ and is produced with titanium coating to prevent damage to interference data and external effects. The accelerometer has a measurement frequency of up to $1 \mathrm{kHz}$.

\subsection{Data Processing}

The collected raw data may be insufficient to reach the desired result or use in control applications. Data processing is an important step in recalculating and filtering of signals, revealing signal statistics and ultimately achieving the desired result.

\section{Filtering of Acceleration Data}

It is of great importance to clean and analyze the signals in order to use the raw data collected from the system. Filtering, one of the most basic applications of signal processing studies, can be used for different purposes such as decreasing or increasing certain frequencies, decreasing or increasing the signal amplitude, cleaning and analyzing unwanted signals.

Filters can also be used to condition a time history signal by reducing unwanted frequency content. In active control applications, filtering processes are often used to eliminate a disturbance or model 
the response of a physical system. It is possible to see both IIR (Infinite Impulse Response) and FIR (Finite Impulse Response) applications in active control applications. The formulas for FIR and IIR are detailed in Eq. 7 and 8.

$$
\begin{aligned}
& y(n)=\sum_{k=0}^{N} a(k) x(n-k) \\
& y(n)=\sum_{k=0}^{N} a(k) x(n-k)+\sum_{j=0}^{P} b(j) y(n-j)
\end{aligned}
$$

In these equations, ' $x(n)$ ' is the input series in time, 'Y (n)' is the time series at the output, ' $n$ ' is the total number of data points of the input signal in the time domain, with the series called 'a (k)' filter ' $\mathrm{a}$ ', ' $\mathrm{N}$ 'and' $\mathrm{P}$ 'are the number of terms in the filters, also referred to as' rank' and 'number of links' respectively. For example, FIR filter is implemented between $\mathrm{k}=0$ and $\mathrm{k}=\mathrm{N}$.

\section{Integral of Acceleration Data}

It is often not possible to use the raw data collected from the system directly. Especially, in order to use the acceleration data from the system in sensitive active control applications, the acceleration data must be converted into displacement data. Thus, more accurate results can be obtained. The most important method used to convert acceleration data to position data is integrating [25].

The triaxial acceleration data collected during machining are arranged in the DewesoftX software interface and converted into displacement data to be input in active control applications. Then, the displacement data were input to the control model from the same point as the point where data was collected under real conditions.

\section{Fast Fourier Transform (FFT)}

The Fourier transform, developed by the French mathematician Jean-Baptiste Joseph Fourier, argues that any function can be written as the sum of sine and cosine functions, and the amplitude of the sine and cosine waves can be determined using the integral [26]. The basic equation used for the Fourier transform is given in Eq. 9. In the equation; $S x(f)$ is the output of the Fourier transform in the frequency domain, $x(t)$, the function due to time and the frequency in radians $2 \pi f[27]$.

$$
S_{x}(f)=\int_{-\infty}^{+\infty} x(t) e^{-j 2 \pi f t} d t
$$

FFT can be used to determine the high frequency values in any signal. These frequencies can cause unwanted noise or vibration. FFT analysis is also widely used in the monitoring and fault detection of the vibration state of machine elements in constant motion such as bearings and gears. FFT analyzes, which have an important place in space, aviation and automotive industry, are performed by using multiples of two $(512,1024,2048)$ samples in the time block [28]. 
The general equation for FFT is given in detail in Eq. 10 and 11, and $k$ row represents the frequency element, $N$ number of samples, $i$ square root (-1) value, $x(i)$ sampled signal data, $n$ represents the index of the sample waiting to be processed.

$$
\begin{aligned}
& \sum_{n=0}^{N-1} x(n) e^{-j n} \omega_{k}(k=0,1,2, \ldots \ldots, N-1) \\
& X k=\sum_{n=0}^{N-1} x[n] * e^{-i^{*}\left(2 \pi^{*} k^{*} n / N\right)}
\end{aligned}
$$

Within the scope of this study, in order to obtain information about the vibration that occurs during the turning process, FFT analysis has been carried out and examined for the acceleration data collected. Thus, information was obtained about what the operating frequency of the system was during processing, what the natural frequency range was and what the sampling number should be in data collection.

\section{ACTIVE VIBRATION CONTROL \\ 3.1. Sliding Mode Control Theory}

In recent years, Sliding Mode Control (SMC), which has been used in many areas with increasing acceleration and is among nonlinear control methods, is preferred especially for meeting high speed control needs. Among the biggest advantages of SMC are the ability to change the dynamic behavior of the system, to reduce the degree of the system and to minimize disruptive effects. SMC is preferred as an effective control approach against systems that cannot be modeled dynamically, variable parameters and distorting effects [29].

In sliding mode control consisting of sliding and reaching stages, equivalent and switching rules must be realized, respectively [30]. So many functions such as tanh, sgn etc. are used to overcome the chatter problem, which is one of the biggest disadvantages of sliding mode control [31]. Tracking error $e(t)$ to find the control input $u(t)$ in sliding mode control can be defined as follows

$$
e(t)=r(t)-x(t)
$$

In the Eq. (12), $e(t)$ is the tracking error, $r(t)$ is the command signal, and $x(t)$ is the measured signal. Sliding surface function can be expressed as

$$
s(t)=\left(\lambda+\frac{d}{d t}\right)^{n-1} e(t)
$$

If assumed that $\mathrm{n}=2, \lambda=2$, equation 14 is obtained.

$$
s(t)=\lambda e(t)+\dot{e}(t)
$$

In this equation, $\lambda$ is a positive constant and if this equation is derivative, Eq. 15 is obtained.

$$
\dot{s}(t)=\lambda \dot{e}(t)+\ddot{e}(t)
$$


Substituting $r-x$ for $e$ in this equation, Eq. 16 is obtained.

$\dot{s}=\lambda \dot{e}+\ddot{r}-A \dot{x}-B x+C u$

The control input $u(t)$, which is the sum of the equivalent $\operatorname{control}\left(u_{e q}\right)$ and switching $\operatorname{control}\left(u_{s w}\right)$, is given in Eq. 17.

$u(t)=u_{e q}(t)+u_{s w}(t)$

Due to the nature of the sliding mode controller, $\dot{s}=0$ is expected. If equation 17 is arranged for $\dot{s}=0, u_{e q}$ can be expressed as follow

$u_{e q}=\frac{1}{C}(-\lambda \dot{e}(t)-\ddot{r}(t)+A \dot{x}(t)+B x(t))$

With $k_{s w}=0.5$ and $\Omega=0.1$, Switching function, $u_{s w}$ can be expressed as in Eq. 19

$u_{s w}(t)=k_{s w} \tanh (s(t) \Omega)$

Acceleration data received from the cutting tool was used as feedback information in the turning process. With the help of the acceleration data, the necessary reaction force for the actuator is calculated. The closed loop used for control is shown in Fig. 4.

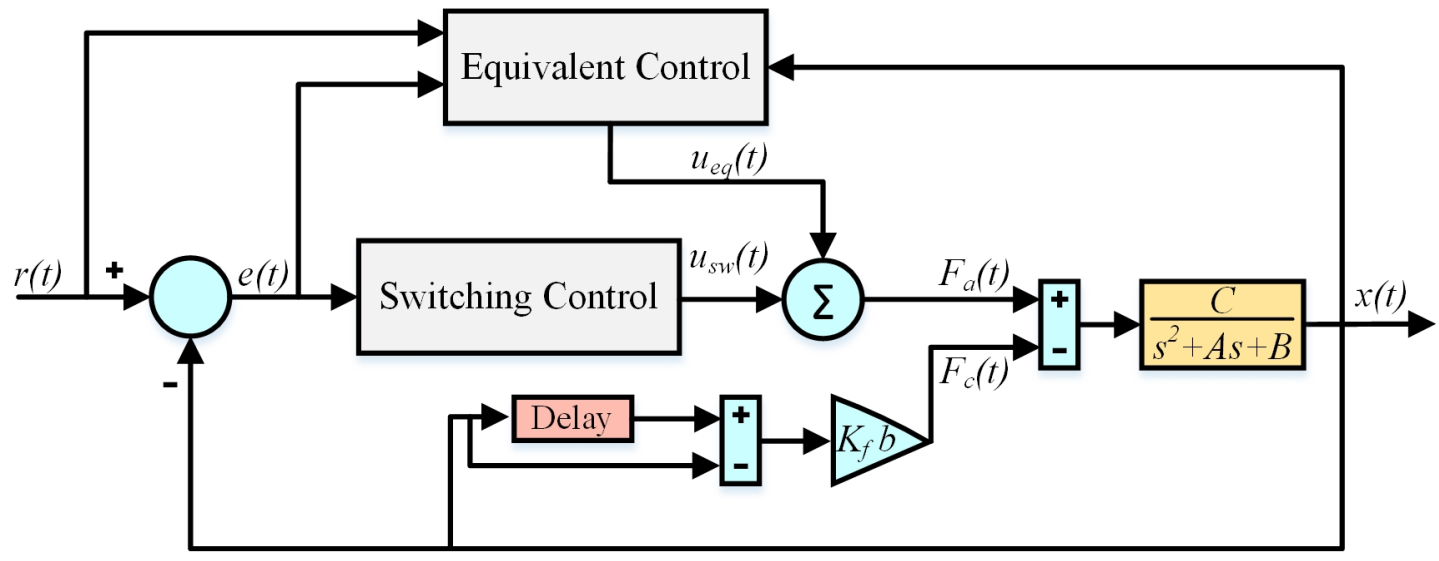

Fig. 4. SMC system block scheme

\section{RESULTS AND DISCUSSION}

Within the scope of the experiments, chatter vibrations generated on the tool holder were collected and evaluated for three different cutting axes with the help of a triaxial PCB brand industrial accelerometer and Dewesoft/Sirius data collection device. The accelerometer is rigidly fixed on the tool holder without using any damping element.

For the active control application, a data set of $20 \mathrm{~s}$ was chosen from the data collected during turning. Selected data were filtered, integrated and FFT analysis was applied. The amplitude values of the collected data ranged between $110 \mathrm{~m} / \mathrm{s} 2$ in the positive direction and $-132 \mathrm{~m} / \mathrm{s} 2$ in the negative direction, and the data collection rate was realized as 2000 (2000 samples / s) per second. 
In order to determine the operating frequencies of the system, the vibration data collected was first subjected to FFT and critical frequency values were determined. After FFT analysis, it was observed that $110 \mathrm{~Hz}$ was the critical frequency value. This value is in the range of chatter vibration seen in the literature, and confirms the study by Munoa in 2016, where he also mentioned the range of chatter vibrations (20-200 Hz) [32]. The FFT analysis result is given in detail in Fig. 5.

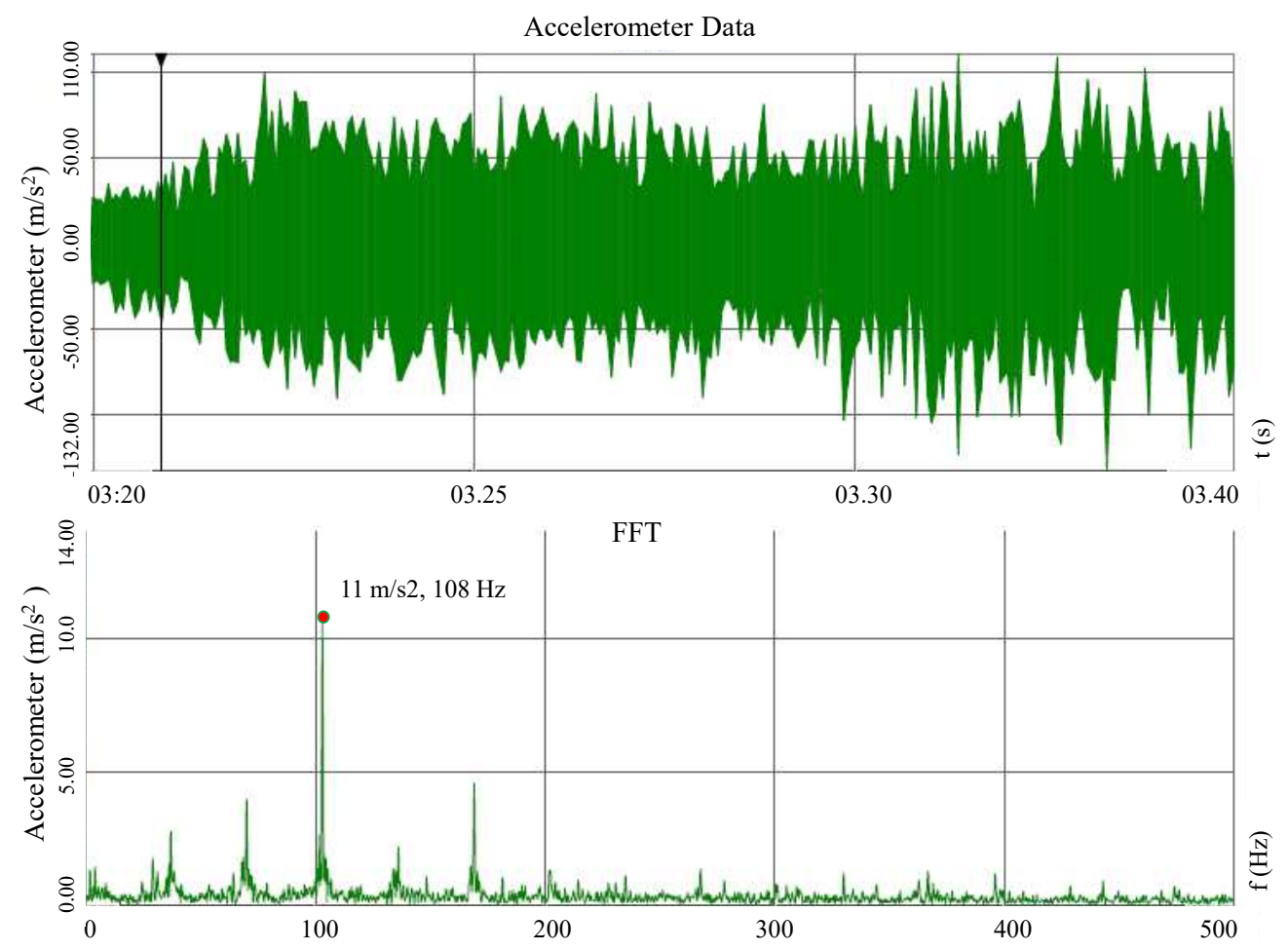

Fig. 5. FFT analysis results

In order to use the raw data collected from the system, it is of great importance to analyze the signals and to clean the unwanted signals. IIR or FIR filters are generally used in active control applications [33]. FIR filtering method was used to clean the parasitic data contained in the acceleration data and to obtain a clean data set that can be used in active control.

The triaxial acceleration data collected during turning are arranged in the DewesoftX software interface and converted into displacement data by taking its integral so that it can be input in active control applications. The 20 seconds of data used for SMC is given in the Fig. 6. 


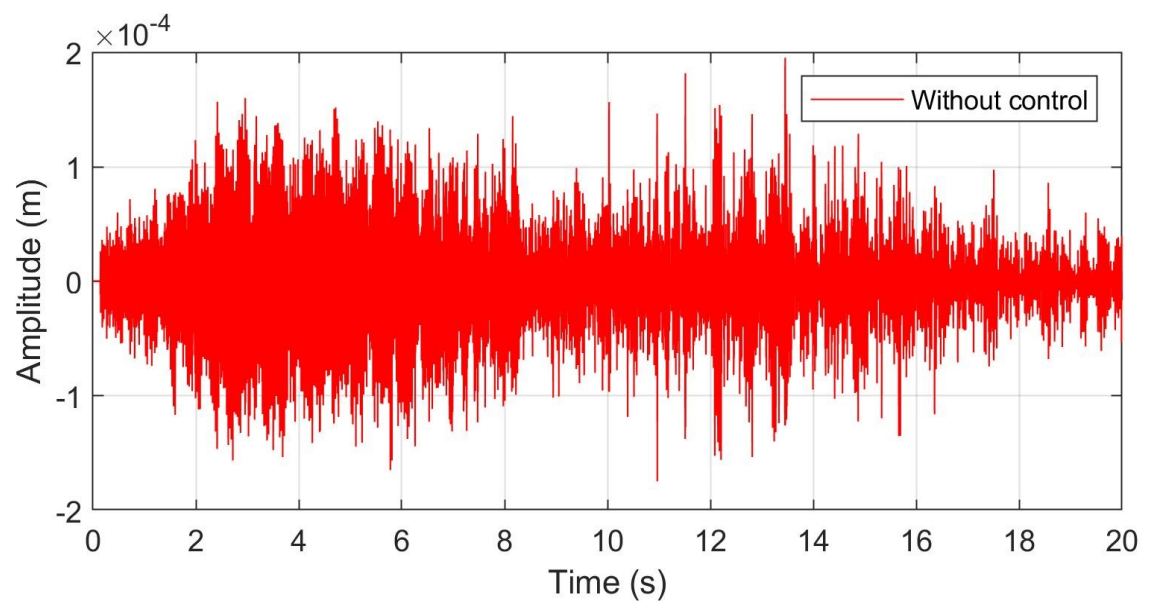

Fig. 6. Uncontrolled 20 seconds accelerometer data

Then, the displacement data were input to our SMC model from the same point as the point where the data was collected under real conditions, and the control of the model during processing was provided for 20 seconds. The displacement graph obtained after active control is given in the Fig. 7.

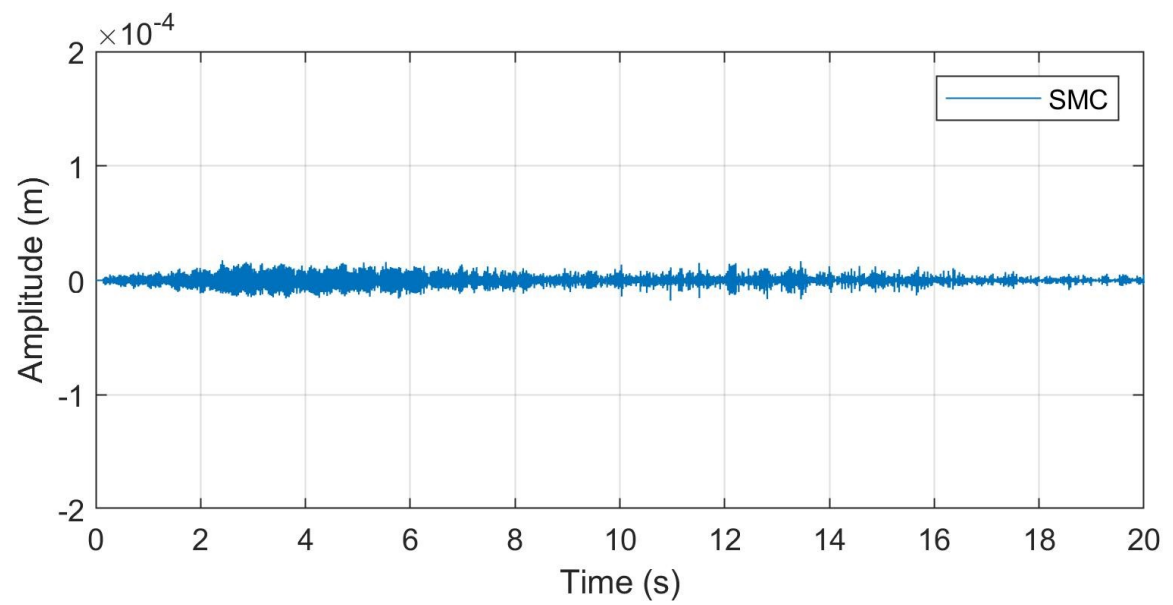

Fig. 7. Displacement data after active SMC

While the displacement data were between 300-500 $\mu \mathrm{m}$ before control, it was observed to be between 50-100 $\mu \mathrm{m}$ after the control. This significant difference will allow us to obtain a high quality product during turning. According to the information obtained from previous studies, chatter vibrations occur with an average displacement amplitude of 200-300 $\mu \mathrm{m}$. In Figure 8, there is a visual of the surface roughness after normal turning and chatter vibration $[4,5,32,34]$. 


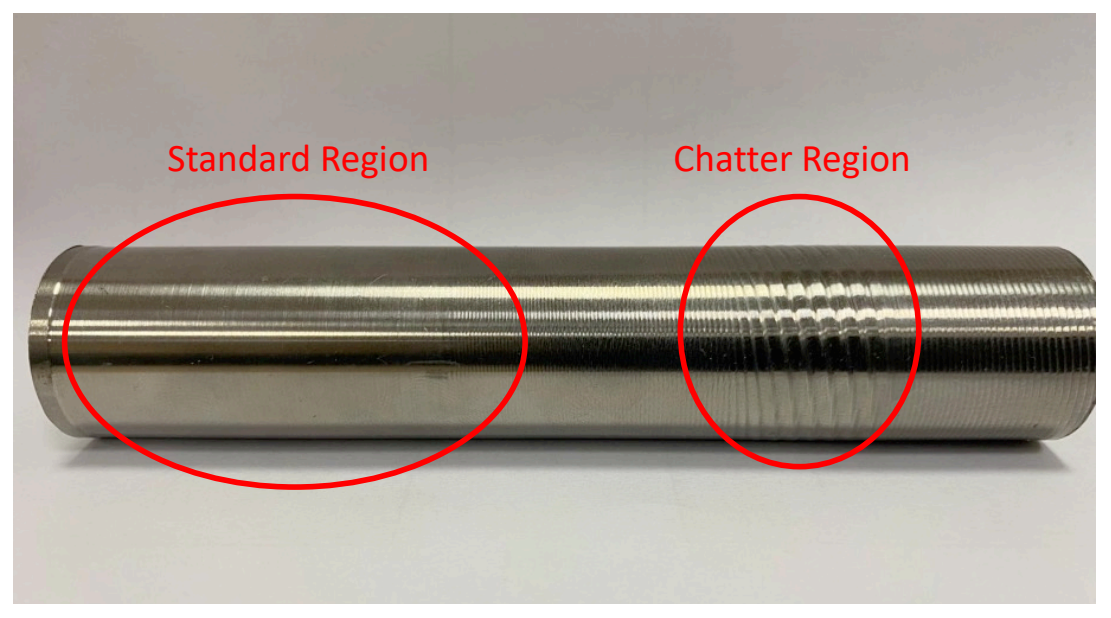

Fig. 8. Surface roughness after turning for Ti6Al4V workpiece

In Fig. 8, there is a visual where the data obtained as a result of the active control is compared with the chatter data received from the system. As can be deduced from the visual, there has been a serious improvement in the quality of the surface roughness due to the decrease in the vibration amplitudes that occur during turning as a result of the active SMC of the cutting tool.

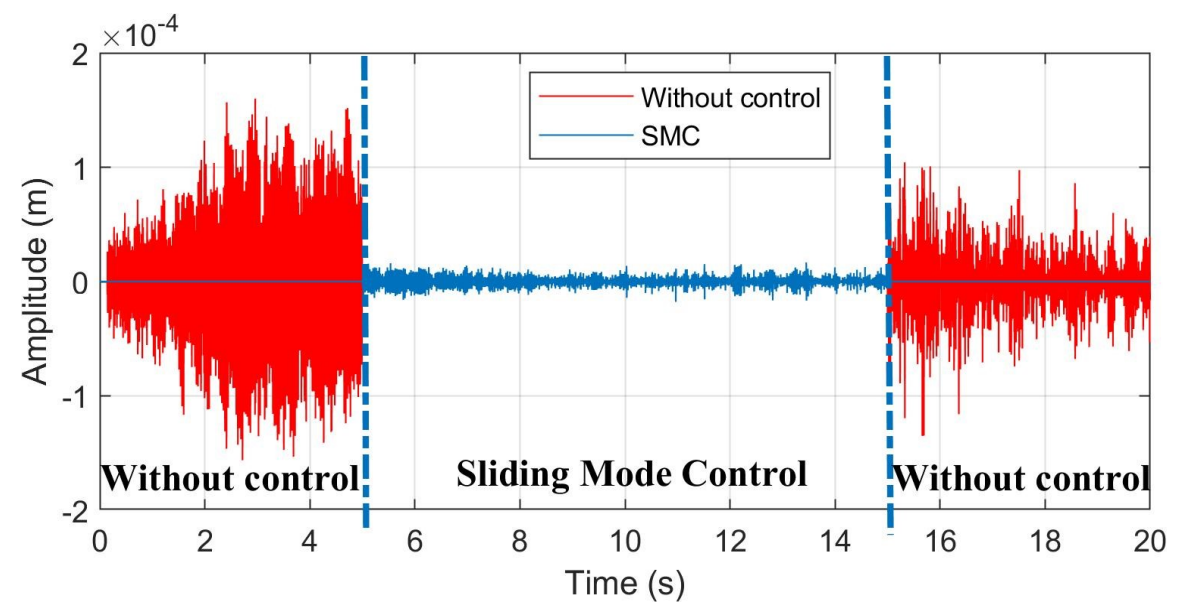

Fig. 8. Data from controlled and uncontrolled situations

It has been determined that the actuator generates a force of up to $25 \mathrm{~N}$ in order to decrease the amplitude during active control. As a result of the literature researches, it was seen that an actuator force of $18 \mathrm{~N}$ is required for active control of AA6025 aluminum alloy during turning, and $45 \mathrm{~N}$ for turning of $\mathrm{C} 45$ quality steel $[14,35]$. It is advocated that the force required by the actuator in active control applications varies depending on the mechanical properties of the workpiece, the properties of the cutting tool and the turning parameters. The information obtained from the literature confirms the results we obtained. The actuator force graph is given in the Fig. 9 for active control application. 


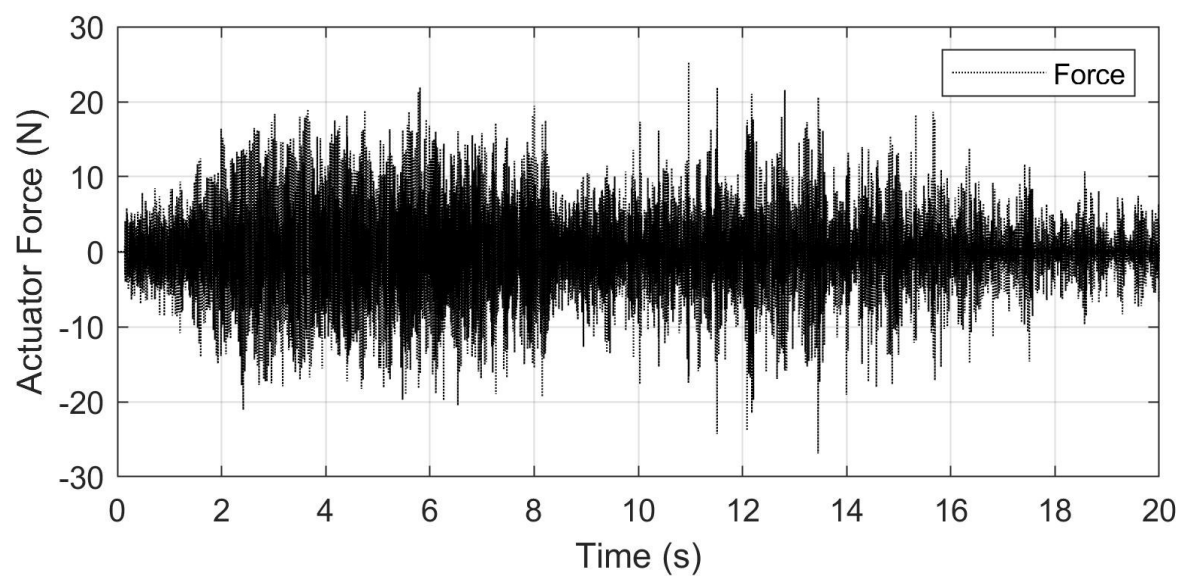

Fig. 9. Reaction force of actuator

FFT analysis of displacement data is given for uncontrolled and controlled situations, respectively, in Fig. 10 and 11. According to the FFT results, there has been a significant decrease in the critical frequency amplitude. This situation has revealed that the amplitude and frequency of the vibration that occurs after the control is too small to affect the product quality and system elements negatively.

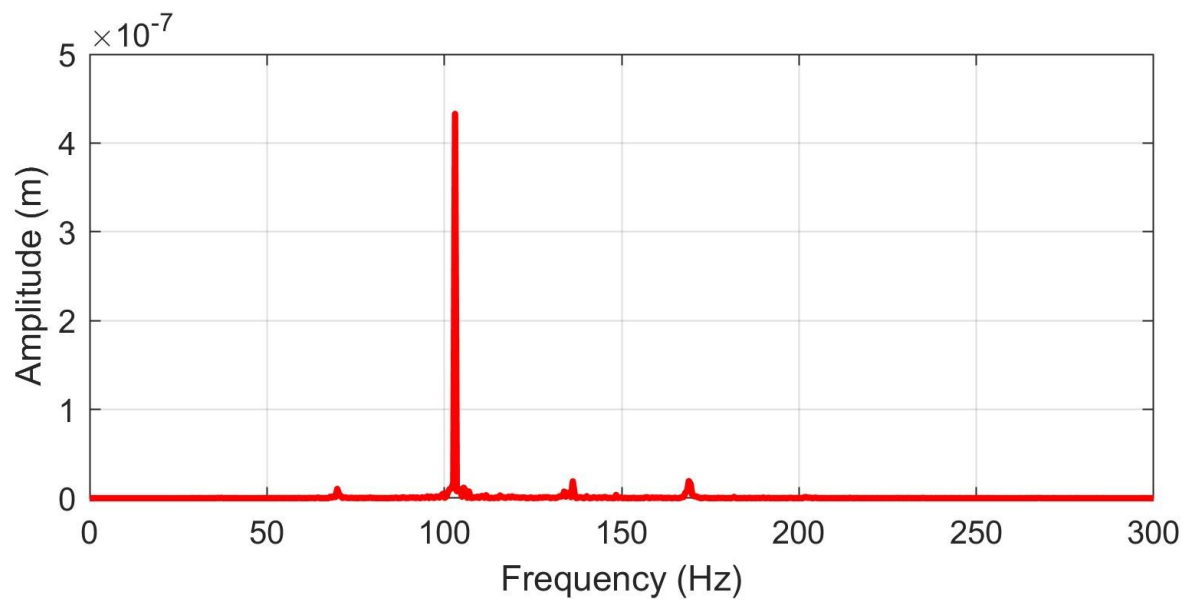

Fig. 10. FFT results for displacement data without active control 


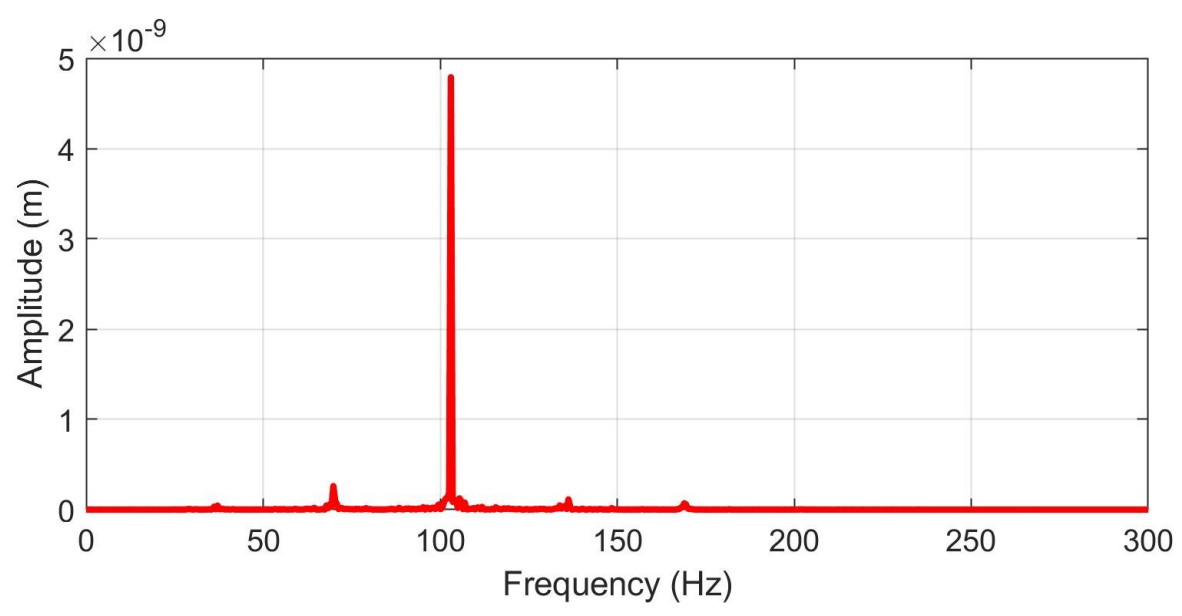

Fig. 11. FFT results for displacement data after SMC

\section{CONCLUSIONS}

In this study, it is aimed to define chatter vibrations that negatively affect product quality and productivity in turning and to reduce them with active control application. Within the scope of the study, acceleration data in three axes were collected from the cutting tool during dry turning of titanium alloy Ti6Al4V quality material. The collected data is processed and then made available in active control applications. According to the results obtained from the study;

D It has been observed that the amplitude values of the acceleration data collected on the tool during the dry turning of Ti6Al4V alloy varies between $110 \mathrm{~m} / \mathrm{s}^{2}$ in the positive direction and $-132 \mathrm{~m} / \mathrm{s}^{2}$ in the negative direction.

$>$ According to the FFT result of the acceleration data, it was observed that the critical frequency values were $110 \mathrm{~Hz}$.

$>$ It was observed that the displacement values before the control were in the range of 250$350 \mu \mathrm{m}$.

> After the active SMC application, it was observed that the displacement data decreased to the range of 50-100 $\mu \mathrm{m}$.

$>$ It was concluded that the FIR digital filtering method is an important step in active control applications.

$>$ It was concluded that the chatter problem, which is one of the major problems of machining, can be solved with active vibration control applications, a correct data acquisition mechanism, controller, system recognition processes and correct actuator selection.

$>$ It is concluded that the SMC works with high accuracy for active vibration control in turning.

$>$ It can be said that SMC is promising with its high accuracy and robustness for future studies.

In line with the information obtained within the scope of the study, it is predicted that piezo and MR-based actuators will be of great importance for active vibration control in turning. 


\section{REFERENCES}

1. Kim DH, Kim TJY, Wang X, et al (2018) Smart Machining Process Using Machine Learning: A Review and Perspective on Machining Industry. International Journal of Precision Engineering and Manufacturing - Green Technology 5:555-568. https://doi.org/10.1007/s40684-018-0057-y

2. Lee WJ, Mendis GP, Sutherland JW (2019) Development of an intelligent tool condition monitoring system to identify manufacturing tradeoffs and optimal machining conditions. Procedia Manufacturing 33:256-263. https://doi.org/10.1016/j.promfg.2019.04.031

3. Yang H, Kumara S, Bukkapatnam STS, Tsung F (2019) The internet of things for smart manufacturing: A review. IISE Transactions 51:1190-1216. https://doi.org/10.1080/24725854.2018.1555383

4. Grzesik W (2017) Cutting Vibrations. Advanced Machining Processes of Metallic Materials 147-162. https://doi.org/10.1016/B978-0-444-63711-6.00008-9

5. Mancisidor I, Barcena R, Munoa J, Etxebarria A (2013) Chatter in Turning. In: 2013 European Control Conference (ECC). EUCA, pp 791-796

6. Siddhpura M, Paurobally R (2012) A review of chatter vibration research in turning. International Journal of Machine Tools and Manufacture 61:27-47. https://doi.org/10.1016/j.ijmachtools.2012.05.007

7. Yavuz H, Mistikoğlu S (2009) Assessment of transition from mechanical engineering to mechatronics engineering in Turkey. International Journal of Engineering Education 25:112-121

8. Thamizhmanii S, Saparudin S, Hasan S (2007) Analyses of surface roughness by turning process using Taguchi method. Journal of Achievements in Materials and Manufacturing Engineering 20:503-505

9. Berezvai S, Bachrathy D, Stepan G (2018) High-speed camera measurements in the mechanical analysis of machining. Procedia CIRP 00:1-4. https://doi.org/10.1016/j.procir.2018.08.264

10. Yan WY, Al-Jumaily AM (2005) Workpiece deflection compensation using a twodimensional toolpost. Proceedings of the Institution of Mechanical Engineers, Part K: Journal of Multi-body Dynamics 219:393-400. https://doi.org/10.1243/146441905X9917

11. Arriaza OV, Tumurkhuyagc Z, Kim D-W (2018) Chatter Identification using Multiple Sensors and Multi-Layer Neural Networks. Procedia Manufacturing 17:150-157. https://doi.org/10.1016/J.PROMFG.2018.10.030

12. Uekita M, Takaya Y (2017) Tool condition monitoring technique for deep-hole drilling of large components based on chatter identification in time-frequency domain. Measurement: Journal of the International Measurement Confederation 103:199-207. https://doi.org/10.1016/j.measurement.2017.02.035

13. Munoa J, Beudaert X, Dombovari Z, et al (2016) Chatter suppression techniques in metal cutting. CIRP Annals - Manufacturing Technology 65:785-808. 
https://doi.org/10.1016/j.cirp.2016.06.004

14. Ma H, Wu J, Yang L, Xiong Z (2017) Active chatter suppression with displacement-only measurement in turning process. Journal of Sound and Vibration 401:255-267. https://doi.org/10.1016/j.jsv.2017.05.009

15. Jang JL, Tarng YS (1999) A study of the active vibration control of a cutting tool. Journal of Materials Processing Technology 95:78-82

16. Mei D, Kong T, Shih AJ, Chen Z (2009) Magnetorheological fluid-controlled boring bar for chatter suppression. Journal of Materials Processing Technology 209:1861-1870. https://doi.org/10.1016/j.jmatprotec.2008.04.037

17. Harms A, Denkena B, Lhermet N, Tools M (2004) Tool adaptor for active vibration control in turning operations. Proceedings of the 9th International Conference on New Actuators, ACTUATOR $2004694-697$

18. Ma H, Wu J, Yang L, Xiong Z (2017) Active chatter suppression with displacement-only measurement in turning process. Journal of Sound and Vibration 401:255-267. https://doi.org/10.1016/j.jsv.2017.05.009

19. Delijaicov S, Yakabu DY, De Macedo B, et al (2018) Characterization of the surface and mechanical properties of the friction stir welding in tri-dissimilar joints with aluminum alloys and titanium alloy. International Journal of Advanced Manufacturing Technology 95:1339-1355. https://doi.org/10.1007/s00170-017-1306-x

20. Li S, Chen Y, Kang J, et al (2019) Interfacial microstructures and mechanical properties of dissimilar titanium alloy and steel friction stir butt-welds. Journal of Manufacturing Processes 40:160-168. https://doi.org/10.1016/j.jmapro.2019.03.015

21. Singh KK, Kartik V, Singh R (2015) Modeling dynamic stability in high-speed micromilling of Ti-6Al-4V via velocity and chip load dependent cutting coefficients. International Journal of Machine Tools and Manufacture 96:56-66. https://doi.org/10.1016/j.ijmachtools.2015.06.002

22. Khasawneh FA, Munch E, Perea JA (2018) Chatter Classification in Turning using Machine Learning and Topological Data Analysis. IFAC-PapersOnLine 51:195-200. https://doi.org/10.1016/j.ifacol.2018.07.222

23. Suresh Prabhu P, Prathipa R, Shanmugasundaram B (2016) Design and development of two degree of freedom model with PID controller for turning operation. Journal of Measurements in Engineering 4:224-231. https://doi.org/10.21595/jme.2016.15762

24. Schmitz TL, Smith KS (2009) Machining Dynamics. Springer Science \& Business Media New York

25. Tan L, Jiang J (2005) Digital signal processing fundamentals

26. Fourier J (1878) Analytical Theory of Heat. Cambridge Warehouse

27. Mo YC, Su KY, Kang W Bin, et al (2018) An FFT-based high-speed spindle monitoring system for analyzing vibrations. Proceedings of the International Conference on Sensing Technology, ICST 2017-Decem:1-4. https://doi.org/10.1109/ICSensT.2017.8304429 
28. Upase R, Ambhore N (2020) Experimental investigation of tool wear using vibration signals: An ANN approach. Materials Today: Proceedings 24:1365-1375.

https://doi.org/10.1016/j.matpr.2020.04.454

29. Nguyen D (1988) Sliding-Mode Control: Advanced Design Techniques. University of Technology

30. Aydin MN, Coban R (2021) PID sliding surface-based adaptive dynamic second-order fault-tolerant sliding mode control design and experimental application to an electromechanical system. https://doi.org/10.1080/00207179.2021.1871963

31. Iplikci S, Bayrak A, Gürsoy H, Efe MÖ (2017) A novel robust fuzzy control of an uncertain system. Transactions of the Institute of Measurement and Control 39:324-333. https://doi.org/10.1177/0142331216668394

32. Munoa J, Beudaert X, Dombovari Z, et al (2016) Chatter suppression techniques in metal cutting. CIRP Annals - Manufacturing Technology 65:785-808.

https://doi.org/10.1016/j.cirp.2016.06.004

33. Teti R, Jemielniak K, O’Donnell G, Dornfeld D (2010) Advanced monitoring of machining operations. CIRP Annals - Manufacturing Technology 59:717-739. https://doi.org/10.1016/j.cirp.2010.05.010

34. Mancisidor I, Pena-Sevillano A, Dombovari Z, et al (2019) Delayed feedback control for chatter suppression in turning machines. Mechatronics 63:102276. https://doi.org/10.1016/j.mechatronics.2019.102276

35. Zaeh MF, Kleinwort R, Fagerer P, Altintas Y (2017) Automatic tuning of active vibration control systems using inertial actuators. CIRP Annals - Manufacturing Technology 66:365-368. https://doi.org/10.1016/j.cirp.2017.04.051 
Figures

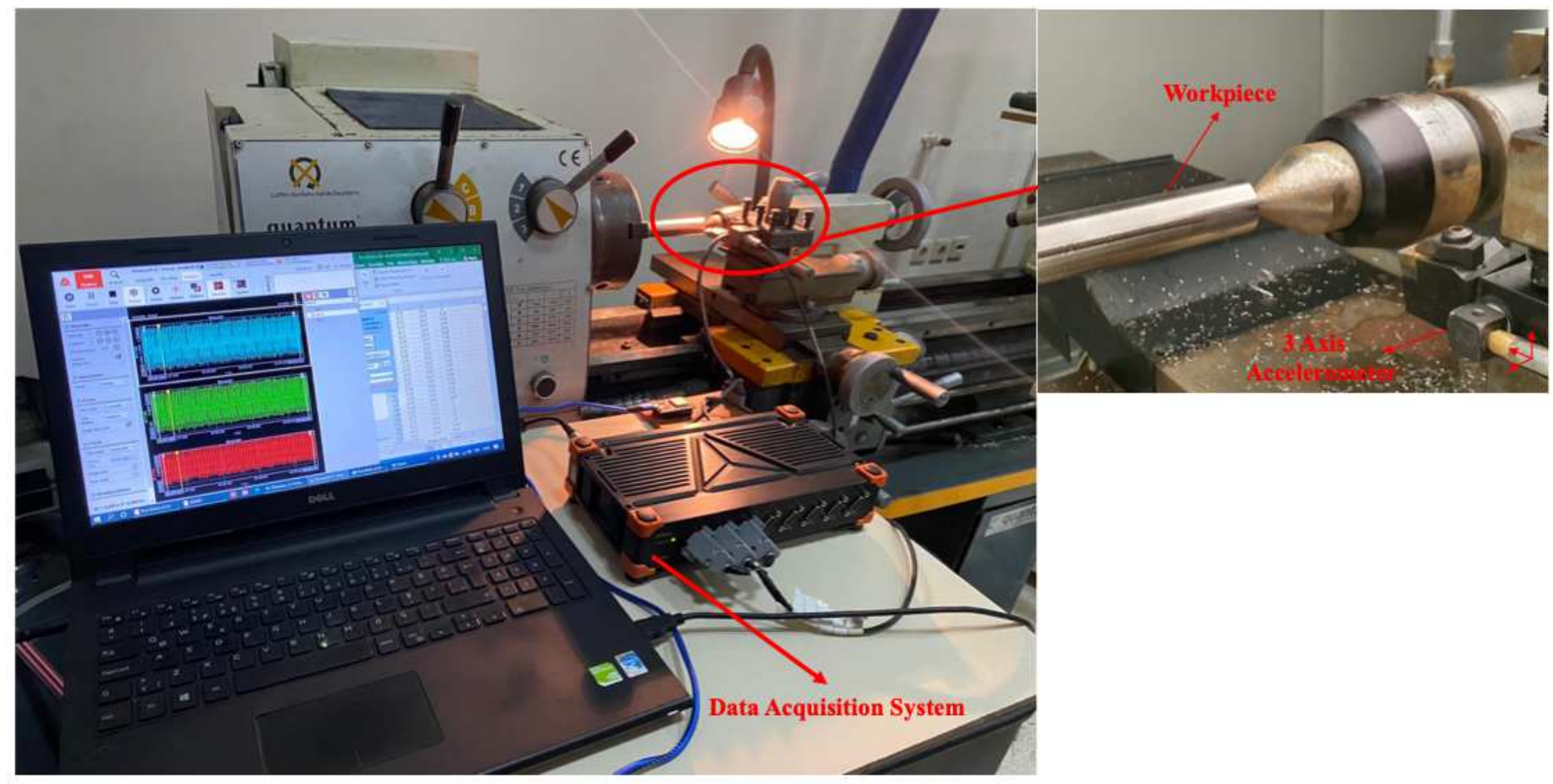

Figure 1

Experimental setup for vibration measurement

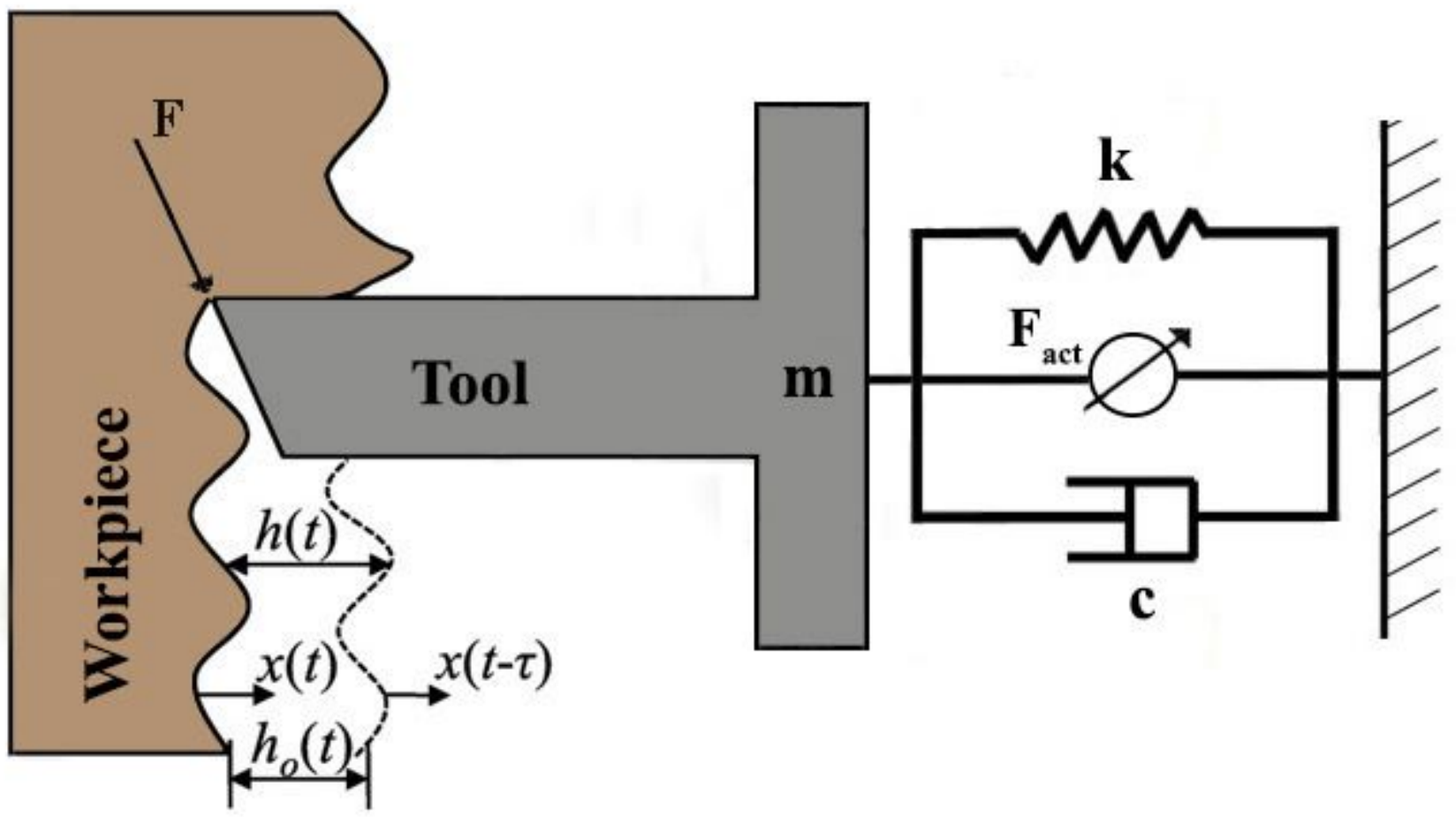

Figure 2 
a)

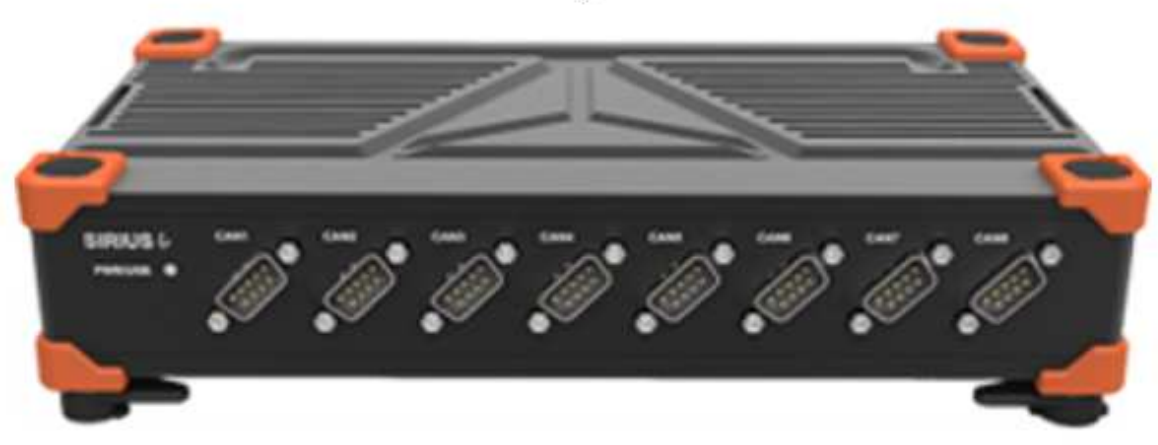

b)

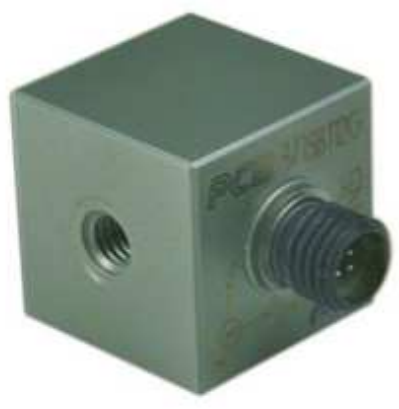

Figure 3

a) Dewesoft Data acquisition device b) MEMS triaxial accelerometer

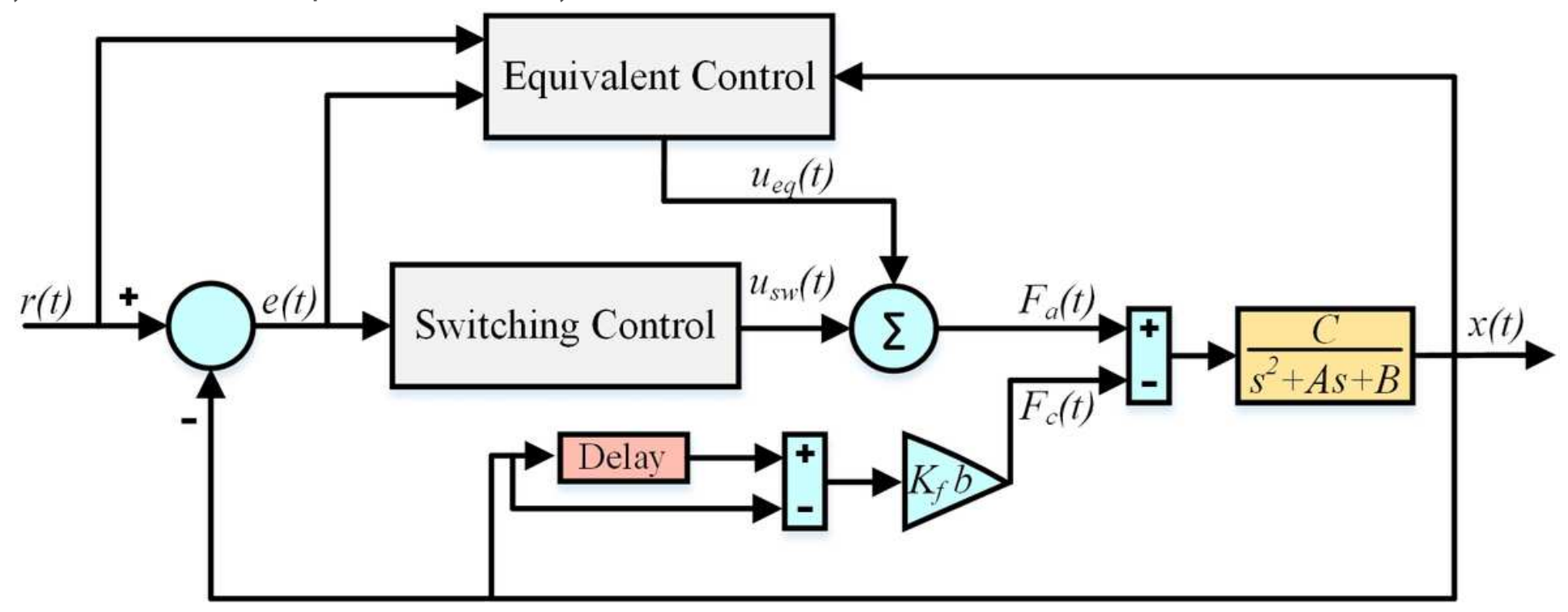

Figure 4

SMC system block scheme 

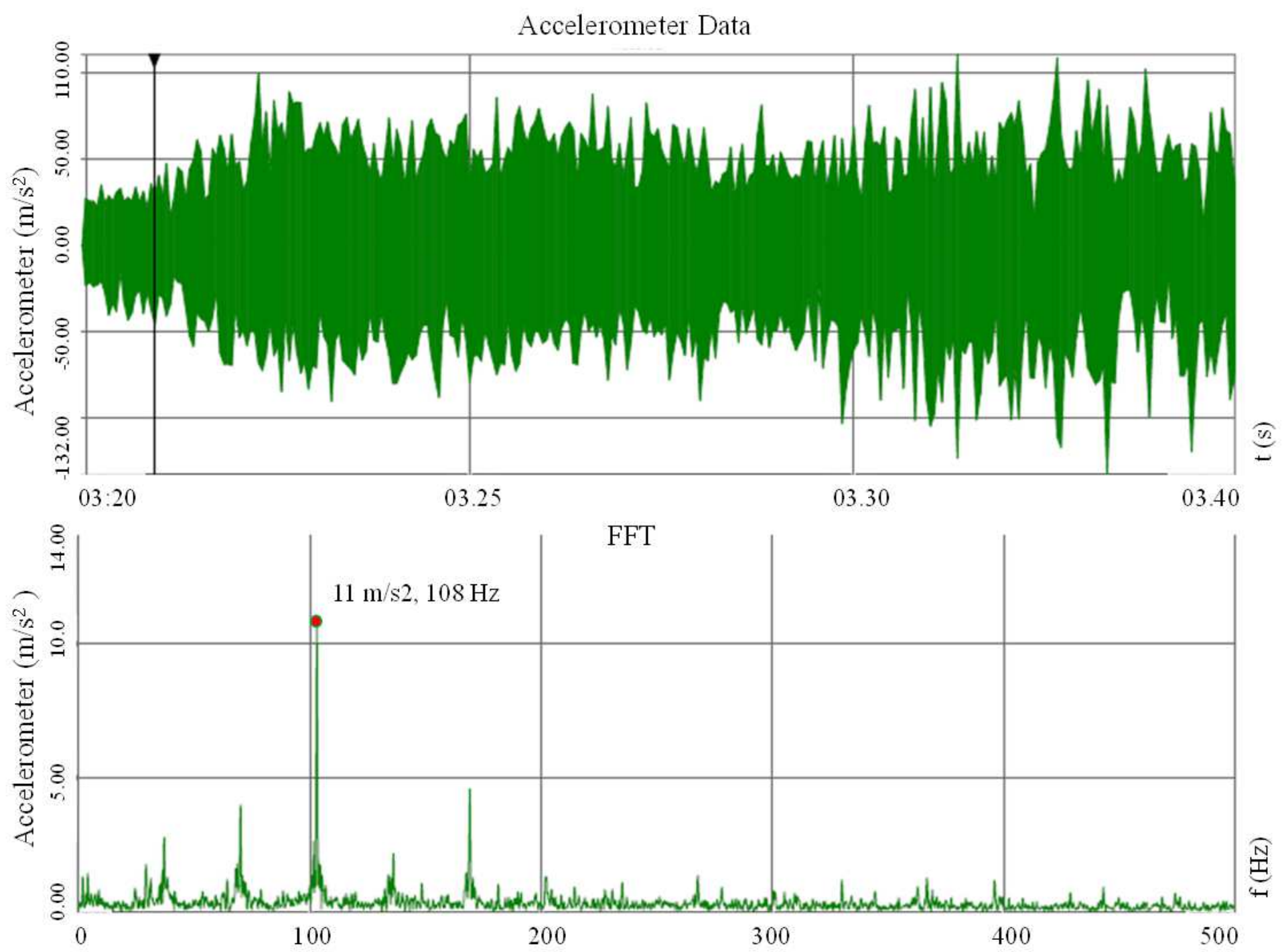

Figure 5

FFT analysis results 


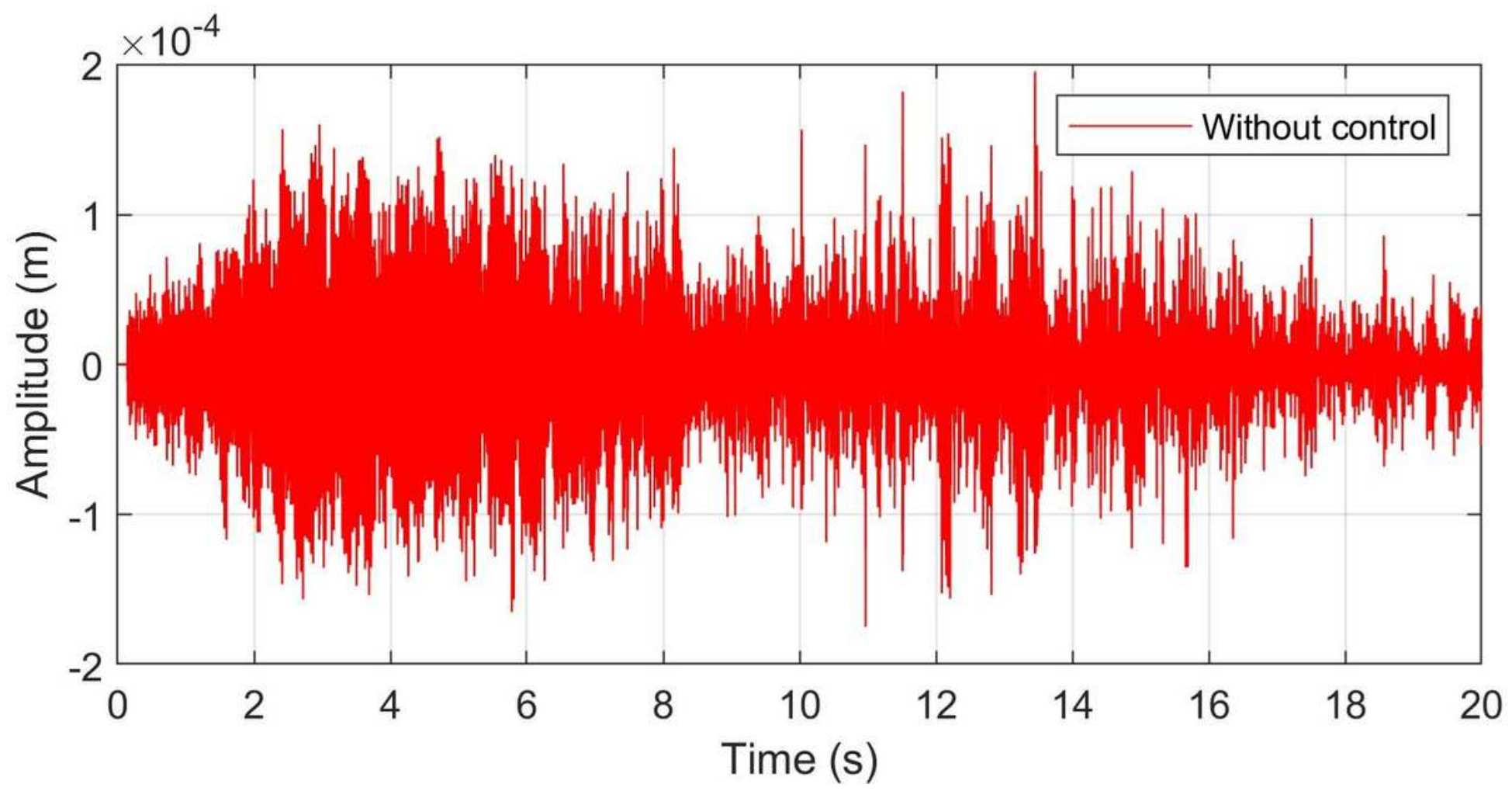

Figure 6

Uncontrolled 20 seconds accelerometer data

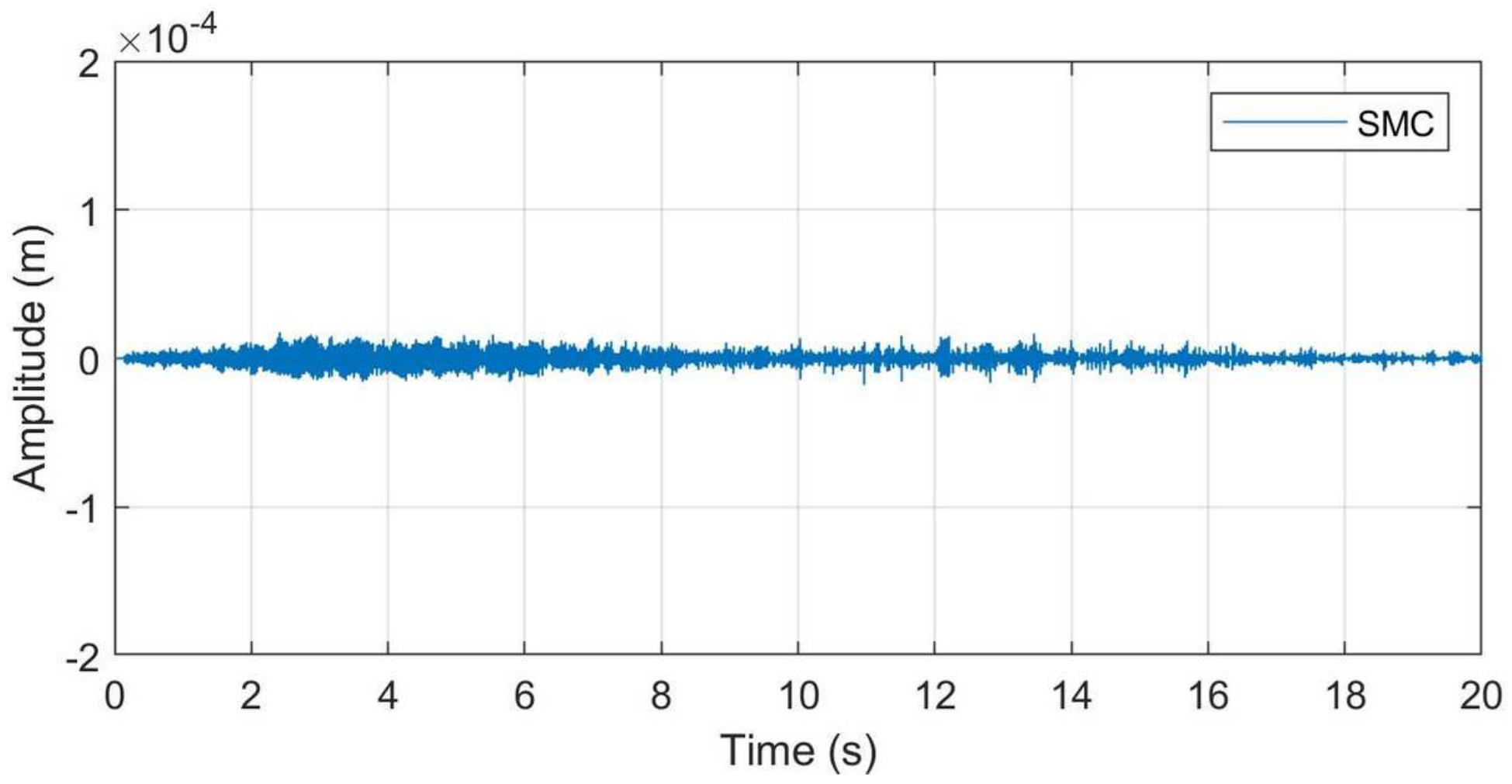

Figure 7

Displacement data after active SMC 


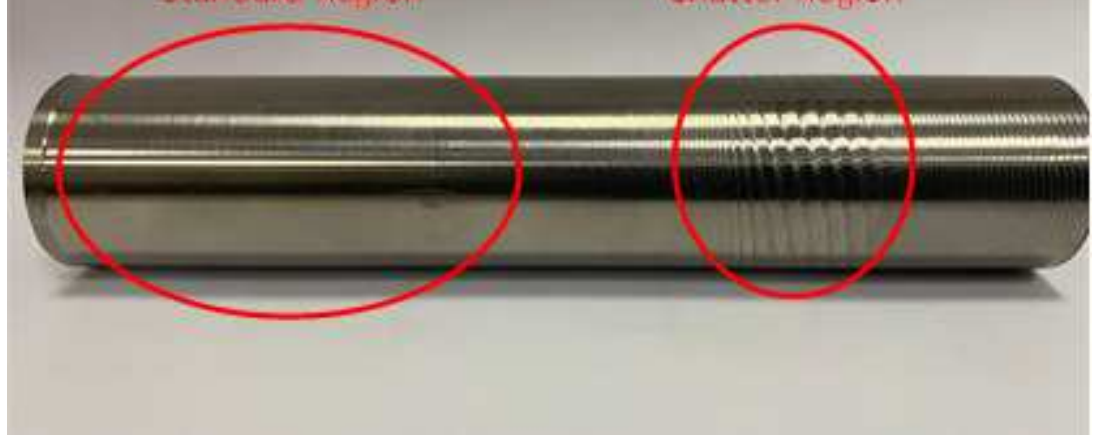

Figure 8

Surface roughness after turning for Ti6Al4V workpiece

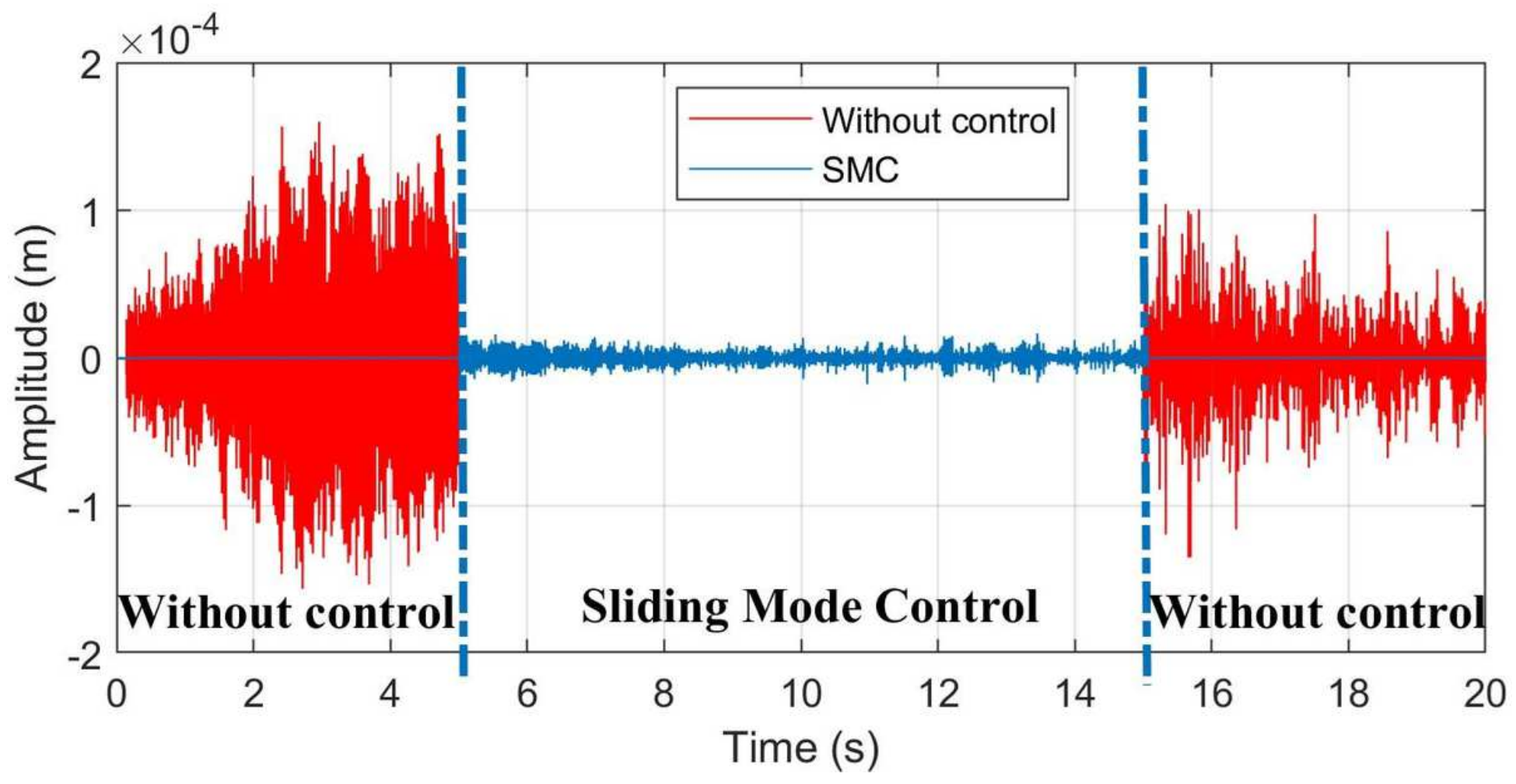

Figure 9

Data from controlled and uncontrolled situations 


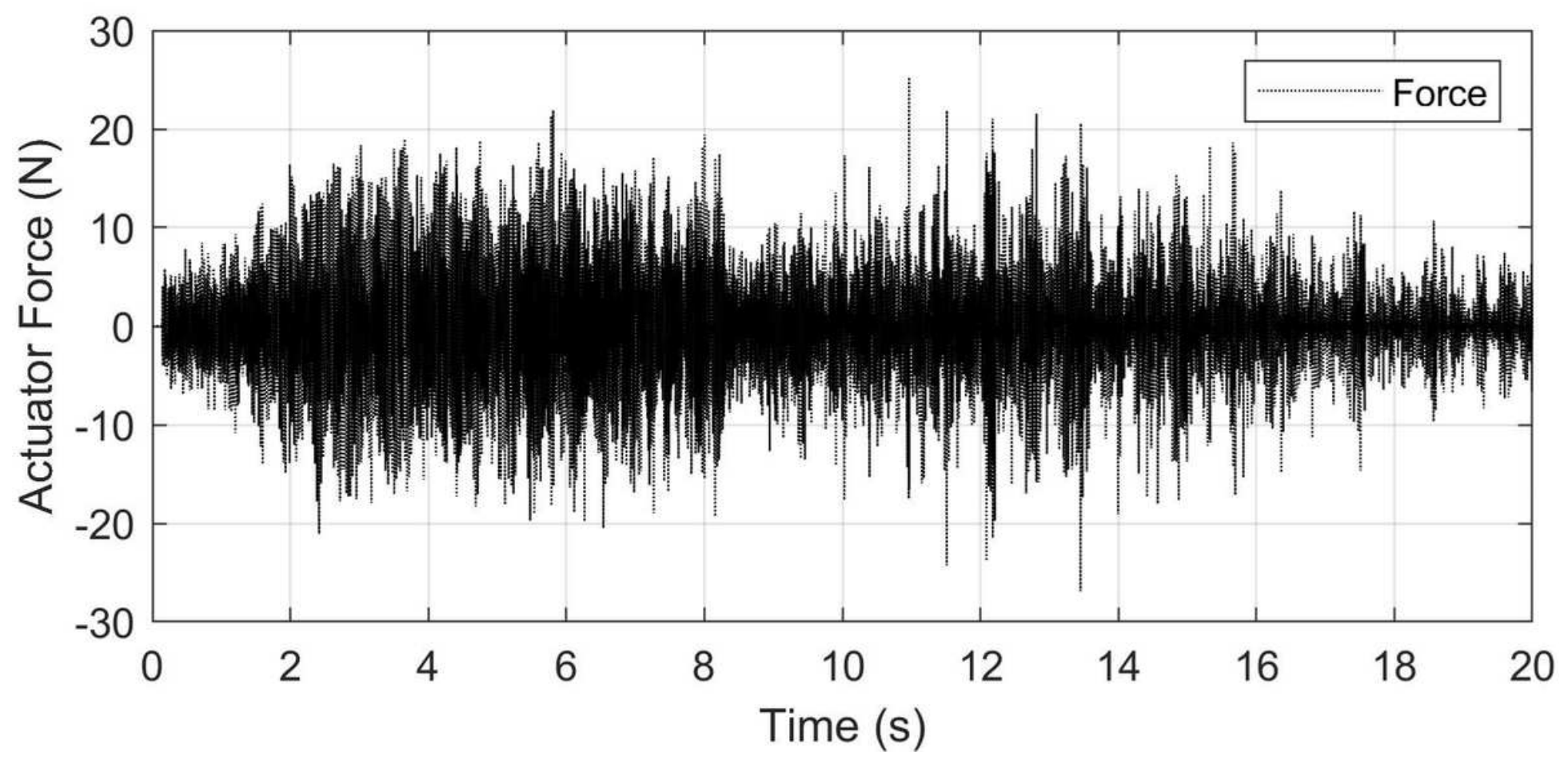

Figure 10

Reaction force of actuator

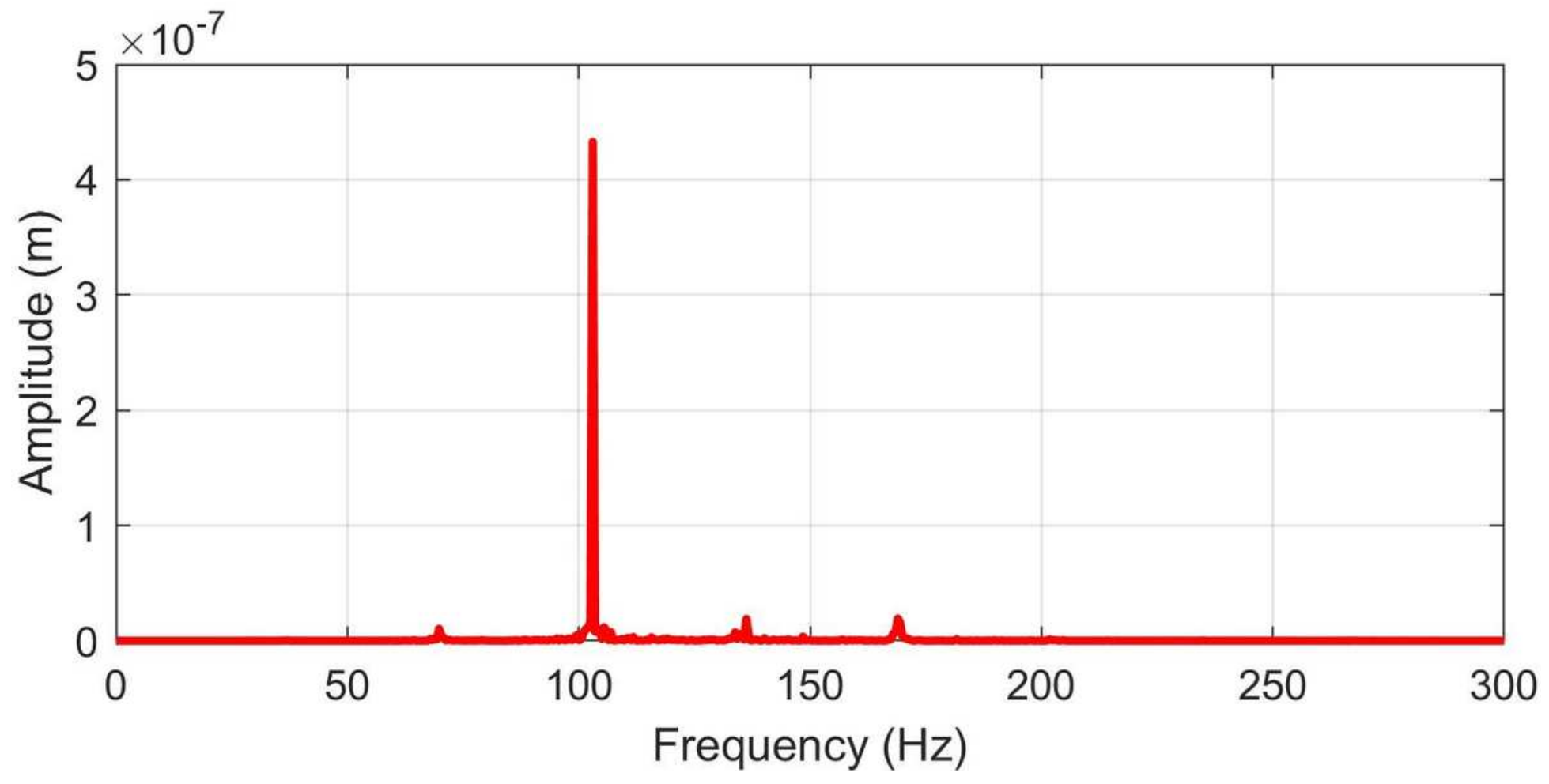

Figure 11

FFT results for displacement data without active control 


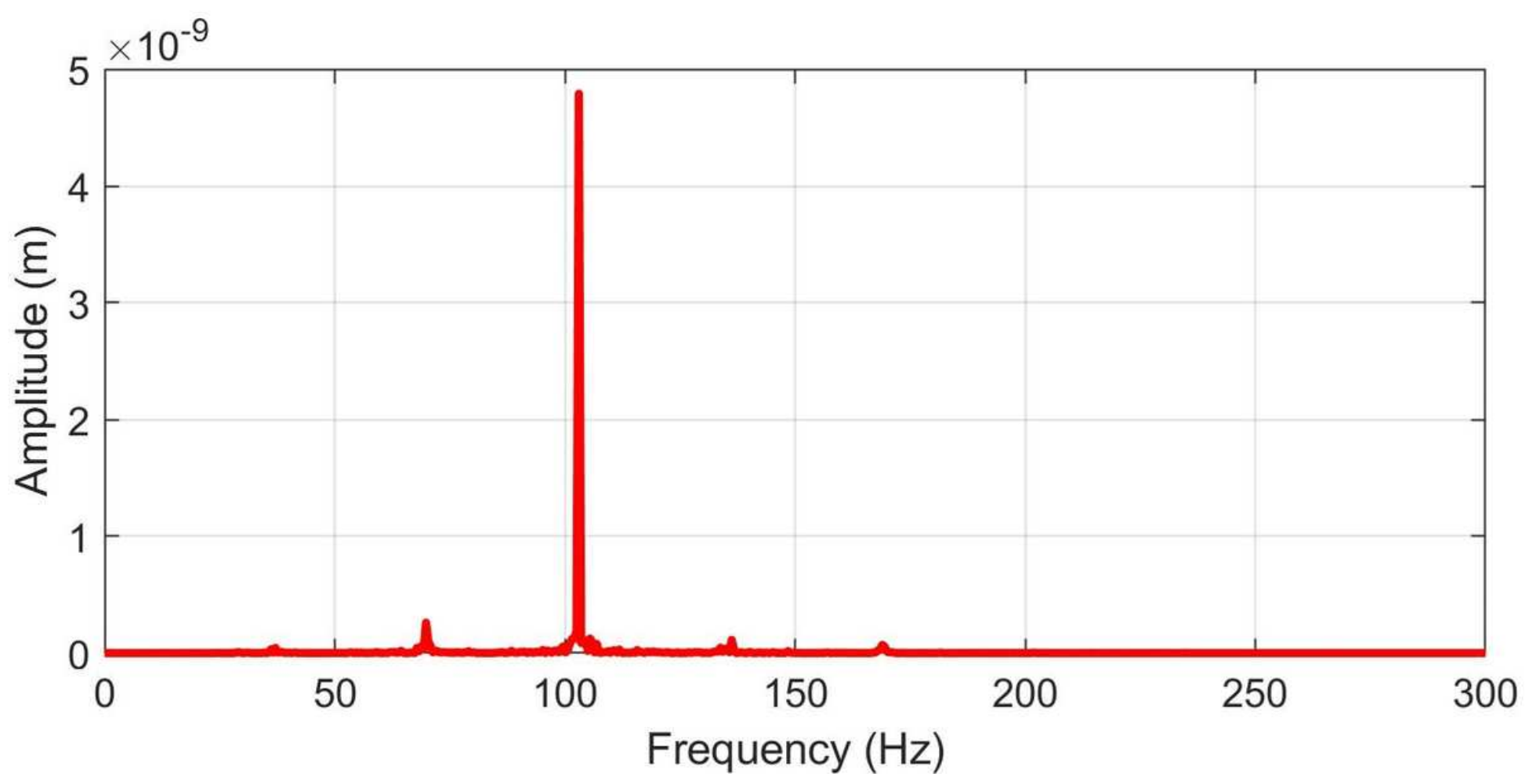

Figure 12

FFT results for displacement data after SMC 